\title{
Acoustic behaviours of large crustaceans in NE Atlantic coastal habitats
}

\author{
Laura Coquereau ${ }^{1, *}$, Jacques Grall $^{2}$, Jacques Clavier $^{1}$, Aurélie Jolivet ${ }^{1,3}$, \\ Laurent Chauvaud ${ }^{1,2}$
}

\begin{abstract}
${ }^{1}$ Université de Bretagne Occidentale, Institut Universitaire Européen de la Mer, Laboratoire des Sciences de l'Environnement Marin, UMR 6539, BeBEST, rue Dumont D'Urville, 29280 Plouzané, France ${ }^{2}$ Observatoire Marin, UMS 3113, Institut Universitaire Européen de la Mer, rue Dumont D'Urville, 29280 Plouzané, France ${ }^{3}$ TBM environnement/Somme, 115 rue Claude Chappe, Technopole Brest Iroise, 29280 Plouzané, France
\end{abstract}

\begin{abstract}
Although many studies have investigated the benthic environment of temperate marine waters, little is known about the acoustic behaviour of the organisms in these habitats, particularly crustaceans. This study focused on the acoustic behaviour of large crustaceans in NE Atlantic coastal regions. A total of 11 crustacean species were recorded in tank-based experiments to identify sound-producing species and the behaviours associated with their sounds as well as to quantitatively characterise and compare the sounds. A total of 34 sounds were associated with behaviours such as moving, feeding, mandible rubbing, swimming, species-specific behaviour and other unidentified behaviours. The sounds included single pulse and pulse train signals that were distributed across a peak frequency spectrum of 3 to $45 \mathrm{kHz}$ with received levels between 93 and $142 \mathrm{~dB}$ re $1 \mu \mathrm{Pa}$ (peak to peak). The results demonstrated that Brachyura had the most diverse sound types. Using a combination of several acoustic features, $24 \%$ of the recorded sounds appeared to have a high potential to be differentiated in field recordings: the feeding sound of Cancer pagurus, Carcinus maenas, Necora puber and Pachygrapsus marmoratus; the species-specific sound of C. pagurus and Galathea squamifera; and the pulse train sound associated with unidentified behaviours of Lophozozymus incisus and N. puber. These findings extend the existing crustacean acoustic library in marine ecosystems and contribute to our understanding of in situ acoustic recordings in temperate regions.
\end{abstract}

KEY WORDS: Acoustic behaviour $\cdot$ Sound library $\cdot$ Crustaceans $\cdot$ Crabs $\cdot$ Snapping shrimps

\section{INTRODUCTION}

Both field and tank-based experiments have shown that a variety of crustacean species can produce acoustic signals. These species include the (sub-) classes Cirripedia and Malacostraca (reviewed by Ewing 1989, Budelmann 1992, Schmitz 2002). Several taxa have been investigated in greater detail, including snapping shrimps (Au \& Banks 1998, Bohnenstiehl et al. 2016), mantis shrimps (Patek \&

\footnotetext{
*Corresponding author: laura.coquereau@univ-brest.fr
}

Caldwell 2006), spiny lobsters (Patek \& Oakley 2003) and semi-terrestrial crabs (Boon et al. 2009). These taxa produce sounds through a variety of mechanisms, including stridulation (Guinot-Dumortier \& Dumortier 1960, Boon et al. 2009), stick-slip friction (Moulton 1957, Patek 2002, Patek \& Baio 2007), carapace vibration (Henninger \& Watson 2005, Patek \& Caldwell 2006, Ward et al. 2011) and cavitation bubble collapse (Knowlton \& Moulton 1963, Versluis et al. 2000). While the behavioural meaning of sound

() The authors 2016. Open Access under Creative Commons by Attribution Licence. Use, distribution and reproduction are unrestricted. Authors and original publication must be credited. 
production is often unclear, several researchers have attributed communicative functions to some sounds (for example, defence against predators, courtship, orientation and agonistic interactions; Boon et al. 2009, Stanley et al. 2010, Buscaino et al. 2015). These crustacean sounds contribute substantially to the marine soundscapes (Patek \& Oakley 2003, Freeman et al. 2014) and may have important information about the local ecology, local populations and, more generally, habitat ecology (Watanabe et al. 2002, Piercy et al. 2014).

Much of our understanding about crustacean sound production comes from recordings of warmwater species. Far less is known about species that inhabit temperate regions where, to date, few studies have been conducted to identify sound production behaviours. The European spiny lobster Palinurus elephas creates sound in association with anti-predatory behaviours (Buscaino et al. 2011, de Vincenzi et al. 2015). The lobster Homarus gammarus frequently produces vibrations when handled or attacked by octopus; this suggests an escape function, analogous to stridulation in palinurids (Bouwma \& Herrnkind 2009). Coquereau et al. (2016) showed that the snapping shrimp Athanas nitescens produces loud snapping sounds, while the spider crab Maja brachydactyla produces at least 3 different sound types: a feeding sound plus 2 sounds that are not associated with particular behaviours. Beyond these examples, the sound production of several common large crustaceans in temperate waters has not yet been investigated.

Although several authors have demonstrated the influence of crustacean species on temperate coastal habitats (Abele 1974, Brown \& Bennett 1980, Sheehy \& Prior 2008), the ecology of the local populations (such as changes in their behaviour, migration and abundance) and their biological rhythms remain poorly understood (Boudreau \& Worm 2012). The use of passive acoustics as a non-invasive tool might be useful to aid in our understanding of ecological phenomena and processes (Butler et al. 2016). The aims of this study were to identify several soniferous large crustacean species inhabiting NE Atlantic coastal regions and to evaluate the extent to which passive acoustics could provide valuable crustacean ecological information in future field recordings. This exploratory study had 3 parts: (1) assessment of crustacean sound production and associated behaviours in tank-based experiments; (2) quantification of the sound characteristics; and (3) comparison of sound production among the studied species.

\section{MATERIALS AND METHODS}

\author{
Animal collection and care
}

Crustaceans were collected from the Bay of Brest in France during the summer of 2015. The selection of the target crustacean species was based on 3 criteria: the crustacean should be a species of megafauna $(>2 \mathrm{~cm}$ ); the crustacean should be common (according to their abundance and overall presence in NE Atlantic coastal habitats); and the acoustics of the crustacean should not have been described previously. A list of 11 species that met these criteria was created: Anomura Galathea squamifera; Brachyura Cancer pagurus, Carcinus maenas, Necora puber, Pachygrapsus marmoratus, Pilumnus hirtellus and Lophozozymus incisus; Caridea Crangon crangon and Palaemon serratus; and Cirripedia Balanus perforatus and Pollicipes pollicipes. Between 3 and 53 individuals of each species were sampled, depending on specimen availability.

The crustaceans were carefully caught by divers or by hand in the intertidal zone. After collection, the animals were transferred to a quiet laboratory (Chorus laboratory, Grenoble INP Foundation) at the Océanopolis public aquarium in Brest. This laboratory is equipped for long-term housing of crustaceans in 6 rectangular glass-sided tanks $(60 \times 50 \mathrm{~cm}$ and $40 \mathrm{~cm}$ water depth) that are continuously supplied with fresh UV- and sand-filtered seawater from the Bay of Brest (temperature: $17-17.3^{\circ} \mathrm{C}$, salinity: $35.0-35.2)$. The crustaceans were distributed by species in 5 tanks (each tank contained 1, 2 or 3 species), and 1 tank was kept for acoustic recordings and was termed the experimental tank. The animals were fed every $2 \mathrm{~d}$ except during feeding experiments, as described in 'Experimental procedures: Identification of sounds and behaviours', with a variety of frozen organisms (shrimp, mussel and pieces of mackerel for Anomura and Brachyura, crushed mussels for Caridea and Artemia spp. for Cirripedia). They were maintained in an $11 \mathrm{~h}$ light:13 h dark cycle.

\section{Experimental procedures}

Sound measurements

The acoustic signals emitted by the crustaceans were recorded using a calibrated HTI-92-WB preamplified hydrophone (High Tech) that had a sensitivity of $-155 \mathrm{~dB}$ re $1 \mathrm{~V} \mathrm{\mu Pa}^{-1}$ and a flat frequency response from 2 to $50 \mathrm{kHz}$. The hydrophone was con- 
nected to an EA-SDA14 compact autonomous recorder set at $14.7 \mathrm{~dB}$ gain (RTSys $\left.{ }^{\circledR}\right)$. Acoustic recordings were acquired with a sampling rate of $156 \mathrm{kHz}$ with 24 bit resolution. The hydrophone was suspended at the centre of the tank and was positioned $11 \mathrm{~cm}$ above the tank bottom.

\section{Identification of sounds and behaviours}

The animals were acclimated to the laboratory conditions for at least 1 mo before the beginning of the experiments. A silicone plate $(0.5 \mathrm{~cm}$ thick $)$ was placed on the bottom of the experimental tank to prevent sound emissions caused by friction between their hard body parts and the glass. Sound recordings were performed separately for each species. Individuals of a given species were randomly collected from the tank where they were housed and released into the experimental tank. The number of individuals in the experimental tank was chosen to mimic the natural abundance as estimated over 2 decades in a coastal habitat long-term survey conducted in Brittany (Grall 2002; data obtained from the Observatory of the Institut Universitaire Européen de la Mer).

Two sets of observations and recordings of sounds were conducted: one set during the day (shorter recordings) to capture potential moving and feeding sounds and another set of longer observations (24 h), which included nights, to capture other potential acoustic behaviours and interactions among individuals. Sounds emitted when the individuals were moving or feeding were selected for analysis because these behaviours are frequently encountered in the natural environment, and they occur year-round. Moving behaviour was recorded in the presence of the substrate on which the species lives (i.e. rock or sand), and no stimulation was used to encourage moving behaviour. The silicone plate, left on the bottom of the tank, was covered by a layer of sand (about $4 \mathrm{~cm}$ ) or by rocks. For the feeding behaviour experiments, the crustaceans were food-deprived for $7 \mathrm{~d}$ to ensure triggering of feeding behaviour during the recordings. All other sounds associated with behaviours that were observed in the tank were recorded and analysed. After being released into the experimental tank, the animals were allowed to adapt to the tank for $1 \mathrm{~h}$ before recording began. After an hour, the crustaceans appeared calm and exhibited normal behaviour. Each recording lasted from 1 to $2 \mathrm{~h}$ and was performed on at least 2 different days. The water flow system was turned off during the recording period to reduce background noise. Recordings were conducted during the day from 08:00 to 19:00 h, which corresponds to the natural daytime period when the study was performed.

To determine the association of acoustic signal production with a particular behavioural event, visual observations and/or video recordings were conducted using a GoPro® HERO3 and were synchronised with the acoustic recordings. We assigned behavioural names to sounds that were produced in clear behavioural contexts (e.g. sounds produced while the animal was feeding or while it was moving on a rock). To avoid anthropomorphic interpretations of sounds that overlap in acoustic features (similar shape, similar acoustic features values) within the species but which lacked a clear behavioural context, we used the terms Type 1, Type 2, etc. We used 'unidentified behaviour' for species-specific sounds when we were not able to establish a clear relationship between the sound and a particular behaviour.

Because many decapod crustaceans are nocturnal and therefore active during dim or twilight hours (Strauss \& Dircksen 2010), each species was recorded over a $24 \mathrm{~h}$ cycle in addition to the shorter recording sessions. Recordings were performed as in the shorttime experiments (density, silicone plate, sound measurements) except that the crustaceans were acclimated in the recording tank for $24 \mathrm{~h}$ before the recording began. A camera was placed on a tripod outside and in front of the experimental tank containing the silicone plate. A neutral red light, to which crustaceans are known to have low sensitivity (Johnson et al. 2002), was mounted overhead so we could determine the association of sound production with behaviours. The acoustic recordings were analysed for $16 \mathrm{~h}$ (12 h of the night phase plus $2 \mathrm{~h}$ before and after the night phase) by scanning for 10 min every $30 \mathrm{~min}$. When acoustic signals were detected, the video footage was viewed.

\section{Data analysis}

\section{Acoustic features of crustaceans}

The sound data (.wav files) were bandpass filtered between 2 and $78 \mathrm{kHz}$ (sampling rate divided by 2) and were analysed using Raven ${ }^{\circ}$, and specific signal processing routines were developed in Matlab®. Sounds either were emitted as a short single transient broadband signal or consisted of a series of pulses. To characterise and quantify the features of 
the acoustic signatures, the signals of each sound type were selected manually. The sound analyses were performed and the acoustic features were processed according to the methods described by Coquereau et al. (2016). Because of reflections from the water surface and from the walls and bottom of the tank, the acoustic parameters are subjected to distortion (Parvulescu 1964, 1967, Akamatsu et al. 2002). Specifically, the duration of the sound is distorted because of the relatively small size of the tanks $(<2 \mathrm{~m}$ in length). Therefore, there could have been reverberation, with the sound persisting in the enclosed space. To limit errors resulting from reverberation of the tank walls, the acoustic measurements were performed on the initial part (the direct path before the echoes arrived, following methods described in Coquereau et al. 2016) of the signals, which are poorly affected by tank artefacts (Fig. 1). Simulations of transient signal emissions were performed previously to evaluate the effects of reverberation on signal features, and these simulations revealed that tank-induced errors do not significantly affect the peak frequency $\left(f_{\mathrm{p}}\right)$ estimations of the initial part of transient signals in experimental tanks (Coquereau et al. 2016). We measured 2 features of the initial part of the signals: (1) the received level (RL; in dB re $1 \mu \mathrm{Pa}$ peak to peak [pp]) calculated in the time window equal to signal selection; and (2) the $f_{\mathrm{p}}$ (in $\mathrm{Hz}$ ), which was defined as the frequency at which the power spectral density ( $\mathrm{dB}$ re $1 \mu^{2} \mathrm{~Pa}^{2} \mathrm{~Hz}^{-1}$ ) was maximal within the selection. The mean, standard deviation (SD) and minimum and maximum values were determined for the acoustic features of each sound type. Median acoustic spectra $\left(\mathrm{dB}\right.$ re $1 \mu^{2} \mathrm{~Pa}^{2}$ $\mathrm{Hz}^{-1}$; the temporal distribution of frequency spectra across the duration of a sound event) between 2 and $50 \mathrm{kHz}$ were determined for each sound type (128-point fast Fourier transform, rectangular window, overlap $50 \%$ ). In addition, to get an idea of the in situ detectability of the sounds that were recorded, in situ estimated detection distances (EDDs) were determined for each sound type, assuming spherical spreading transmission loss. The EDD was calculated using the formula:

$$
\mathrm{EDD}=R_{0} 10^{\frac{\mathrm{RL}-(\mathrm{NL}+8)}{20}}
$$

In this equation, $R_{0}$ is the mean distance $(\mathrm{m})$ between the sound source and the hydrophone, RL ( $\mathrm{dB}$ re $1 \mu \mathrm{Pa}$ ) is the mean received level of a species' sound type, 8 (in $\mathrm{dB}$ ) corresponds to the minimum signal-to-noise ratio needed to detect the signal in noise and $\mathrm{NL}$ is the noise level in $\mathrm{dB}$ re $1 \mu \mathrm{Pa}$. The NL was a mean in situ ambient noise level (ANL $=85.6 \mathrm{~dB}$ ) or

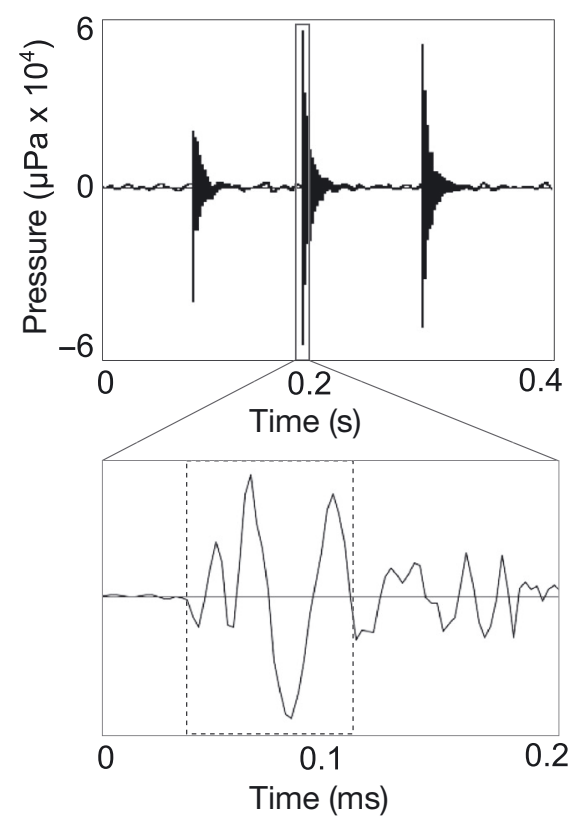

Fig. 1. Selection of a typical clip from which acoustic features were measured (dotted box). We selected the beginning of the transient sound to exclude most wall reverberation. The example here is a sound produced by Cancer pagurus

standard theoretical noise levels computed for open water (Wenz reference curves, Wenz [1962]) for various meteorological conditions: wind speed at 1 knot $(\mathrm{kn})(\mathrm{NL}=77)$ and at $5 \mathrm{kn}(\mathrm{NL}=83)$. The in situ ANL was based on the value calculated by Coquereau et al. (2016) from field recordings in a biogenic habitat in the Bay of Brest. The crustacean species recorded in this study are found in this habitat, and the values are consistent (day and night recordings and replicates at different sites). These calculations are described in detail in Coquereau et al. (2016). For signals composed of a series of pulses, defined as at least 2 pulses that occurred within $10 \mathrm{~ms}$ of each other, we also measured the number of pulses per train, the pulseto-pulse time intervals, the duration of the entire train and the pulse rate (pulses $\mathrm{s}^{-1}$ : number of pulses per train divided by the duration of the entire train) (Fig. 2). The duration of the entire train of pulses was measured to compare signal production in different species, but care should be taken when extrapolating these values to a natural context (Parvulescu 1964, 1967, Akamatsu et al. 2002). Data from Maja brachydactyla (Brachyura) and Athanas nitescens (Caridea), the acoustics of which were previously described in the same laboratory setting and using the same acoustic calculations (Coquereau et al. 2016), were added into the figures for comparison with the crustaceans recorded in this study. 


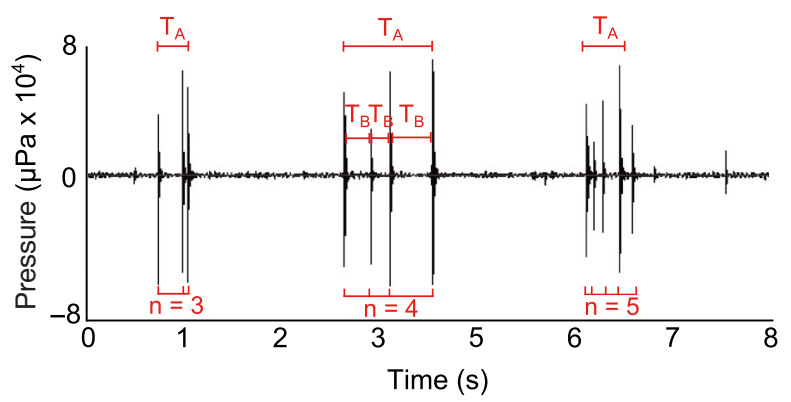

Fig. 2. Representative pulse train signal showing how the following features were measured: the number of pulses per sequence $(n)$, the entire signal duration $\left(T_{A}\right)$ and the pulse-to-pulse time interval $\left(\mathrm{T}_{\mathrm{B}}\right)$. This panel shows regular broad-band pulse sequences produced by Cancer pagurus

\section{Statistical analysis}

The similarities between species for the presence/ absence of acoustic behaviours were compared with a hierarchical method (spherical) of cluster analysis using the Jacquard index (Anderberg 1973). The acoustic features were compared statistically according to species and behaviours. Because the data were not normally distributed (Shapiro-Wilk test, $\mathrm{p}<0.05$ ), the non-parametric Kruskal-Wallis test with Dunn's test was used to assess differences between the acoustic features ( $f_{\mathrm{p}}$ and RL) of signals emitted by the crustaceans (Hollander et al. 2014). The MannWhitney $U$-test was used to compare the characteristics of pulse train sounds (the number of pulses per train, the pulse-to-pulse time intervals, the duration of the entire train and the pulse rate) shared between
2 species. Statistical tests were performed using R Studio $3.0 .2^{\odot}$ software.

\section{RESULTS}

\section{General characteristics of the crustacean sounds}

Analysis of approximately $130 \mathrm{~h}$ of audio/video recordings showed that of the 11 crustacean species investigated in the laboratory settings, 9 produced detectable sounds (Table 1). The 2 species for which no acoustic signals were detected were Balanus perforatus and Pilumnus hirtellus. Overall, 34 different sound types were detected during the recording sessions.

\section{Acoustic behaviours}

Crustacean sounds were produced in different behavioural contexts, including when the animals were moving on rock, moving on sand, swimming, feeding and rubbing their mandibles (Table 1, Fig. 3, see sound library in Supplement 1 at www.int-res. com/articles/b025p151_supp/). Similar pulse train sounds were produced by several species without clear-cut identification of the associated behaviour; we termed this Type 1 sound. The recorded crustaceans also produced species-specific sounds that were associated with specific behaviours (Table 1). These sounds included antennae rubbing for Galathea squamifera, antennule rubbing and an unidentified

Table 1. Recorded crustaceans living in NE Atlantic coastal habitats. x: signals were detected during the recording sessions; ND: no detected signal

\begin{tabular}{|c|c|c|c|c|c|c|c|c|c|}
\hline \multirow{2}{*}{ Recorded species } & \multirow{2}{*}{$\begin{array}{l}\text { No. } \\
\text { ind. re- } \\
\text { corded }\end{array}$} & \multirow{2}{*}{$\begin{array}{l}\text { Total no. of } \\
\text { analysed } \\
\text { signals }\end{array}$} & \multirow[b]{2}{*}{$\begin{array}{l}\text { Moving } \\
\text { on rock }\end{array}$} & \multirow[b]{2}{*}{$\begin{array}{l}\text { Moving } \\
\text { on sand }\end{array}$} & \multirow[b]{2}{*}{ Swimming } & \multirow{2}{*}{$\begin{array}{c}\text { Behav } \\
\text { Feeding }\end{array}$} & \multirow{2}{*}{$\begin{array}{l}\text { iour } \\
\text { Mandibles } \\
\text { rubbing }\end{array}$} & \multirow[b]{2}{*}{ Type 1} & \multirow[b]{2}{*}{$\begin{array}{c}\text { Species-specific } \\
\text { behaviour }\end{array}$} \\
\hline & & & & & & & & & \\
\hline \multicolumn{10}{|l|}{ Anomura } \\
\hline Galathea squamifera & 5 & 284 & $\mathrm{x}$ & ND & ND & $\mathrm{x}$ & ND & ND & $\mathrm{x}$ \\
\hline \multicolumn{10}{|l|}{ Brachyura } \\
\hline Cancer pagurus & 6 & 748 & $\mathrm{x}$ & $\mathrm{x}$ & ND & $\mathrm{x}$ & $\mathrm{x}$ & $\mathrm{x}$ & $\mathrm{x}$ \\
\hline Carcinus maenas & 5 & 482 & $\mathrm{x}$ & $\mathrm{x}$ & ND & $\mathrm{x}$ & $\mathrm{x}$ & $\mathrm{x}$ & ND \\
\hline Lophozozymus incisus & 6 & 296 & $\mathrm{x}$ & $\mathrm{x}$ & ND & $\mathrm{x}$ & $\mathrm{x}$ & $\mathrm{x}$ & ND \\
\hline Necora puber & 4 & 204 & $\mathrm{x}$ & ND & ND & $\mathrm{x}$ & $\mathrm{x}$ & $\mathrm{x}$ & $\mathrm{x}$ \\
\hline Pachygrapsus marmoratus & 3 & 439 & $\mathrm{x}$ & ND & ND & $\mathrm{x}$ & ND & $\mathrm{x}$ & ND \\
\hline Pilumnus hirtellus & 4 & 0 & ND & ND & ND & ND & ND & ND & ND \\
\hline \multicolumn{10}{|l|}{ Caridea } \\
\hline Crangon crangon & 35 & 103 & ND & ND & $\mathrm{x}$ & ND & ND & ND & ND \\
\hline Palaemon serratus & 15 & 252 & ND & ND & $\mathrm{x}$ & $\mathrm{x}$ & ND & ND & ND \\
\hline \multicolumn{10}{|l|}{ Cirripedia } \\
\hline Balanus perforatus & $\sim 50$ & 0 & ND & ND & ND & ND & ND & ND & ND \\
\hline Pollicipes pollicipes & 53 & 111 & ND & ND & ND & ND & ND & ND & $\mathrm{x}$ \\
\hline
\end{tabular}



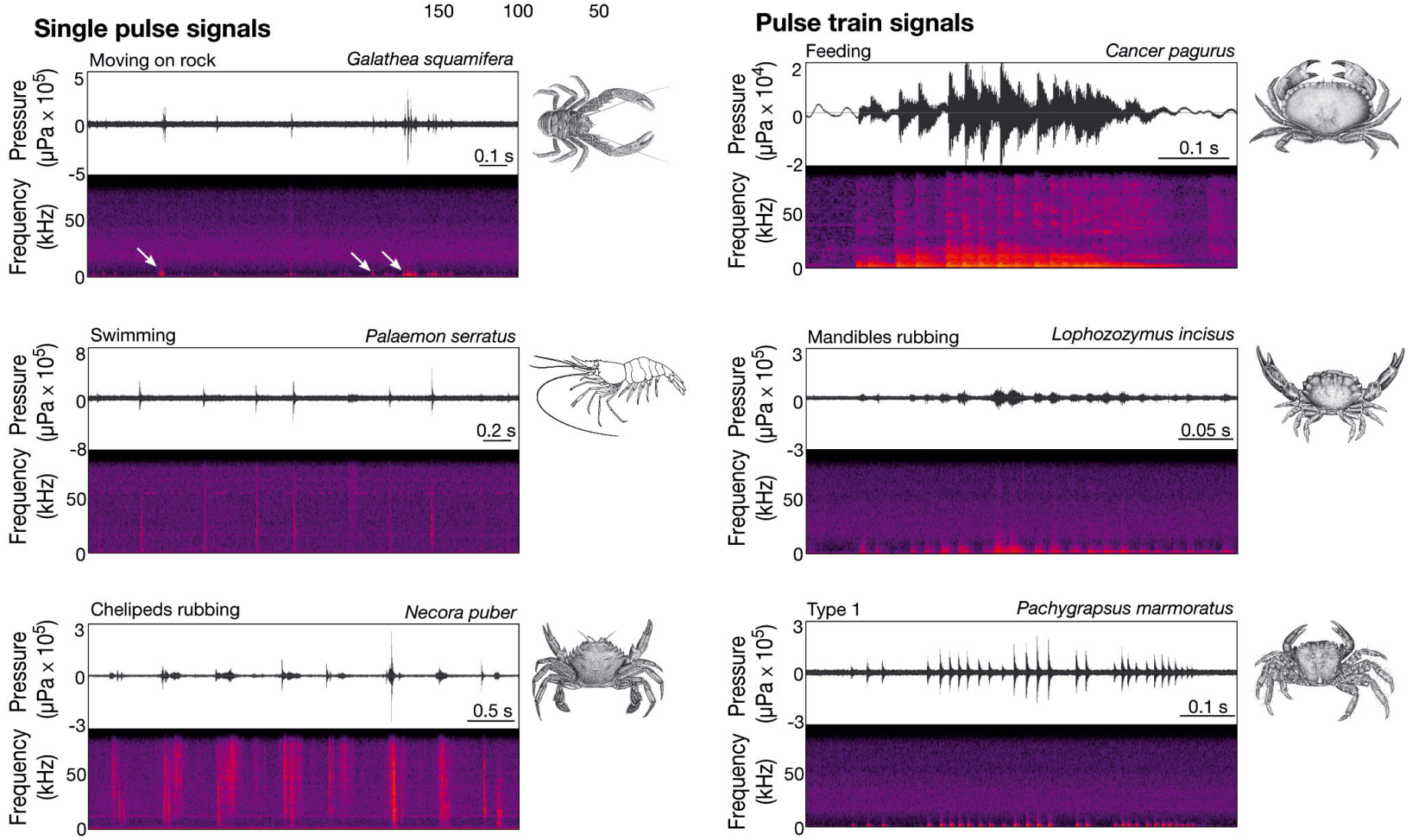

Fig. 3. Examples of waveforms and spectrograms of the sounds recorded in tanks that were produced by crustacean species living in NE Atlantic coastal habitats. The sounds were single pulses or pulse train signals

behaviour that produced a regular broadband pulse train signal for Cancer pagurus, cheliped rubbing and rubbing of mandibles with chelipeds for Necora puber and physical contact between individuals for Pollicipes pollicipes.

The sound types that were identified during the night in the $24 \mathrm{~h}$ acoustic recordings were mostly the same as those identified during the short daytime recordings. The night recordings also showed 3 new sound types: Type 1 sounds for both C. pagurus and Lophozozymus incisus and a sound associated with an unidentified behaviour for C. pagurus that consisted of irregular broadband pulses. These 3 sound types were also found in the daytime portion of the $24 \mathrm{~h}$ recordings, so they were not specific to the night.

Brachyura produced the most different sound types (4 per species on average), followed by Anomura (3 sound types for G. squamifera) and Caridea and Cirripedia (1 per species) (Table 1). Feeding was the most shared acoustic behaviour among the species (recorded for 7 of the 9 soniferous crustaceans). Cluster analysis identified 2 groups with similar acoustic type profiles (Fig. 4): one group comprised Brachyura and Anomura, and a second group comprised Cirripedia and Caridea.

\section{Acoustic features}

The 34 sound types covered a broad spectrum of peak frequencies that ranged from 2.5 to $41 \mathrm{kHz}$ and that had a mean $f_{\mathrm{p}}$ of $19 \pm 9 \mathrm{kHz}$ (Fig. 5). The distribution of the peak frequencies was bimodal (modes of 2.5 to $7.5 \mathrm{kHz}$ and 27.5 to $37.5 \mathrm{kHz}$ ). RLs ranged from 93 to $142 \mathrm{~dB}$ re $1 \mu \mathrm{Pa}(\mathrm{pp})$ with a mean of $107 \pm$ $5 \mathrm{~dB}$ re $1 \mu \mathrm{Pa}(\mathrm{pp})$. RL data were shifted towards a unimodal distribution (mode of 95 to $105 \mathrm{~dB}$ re $1 \mu \mathrm{Pa}$ [pp]). The feeding sounds were mostly composed of low mean peak frequencies (from 4 to $10 \mathrm{kHz}$ ), but they were more or less loud depending on the species (Fig. 5). Acoustic spectra were calculated for the stack of all signal selections for each sound type. Fig. 6 shows examples of the acoustic spectra associated with feeding for 7 species: N. puber, G. 


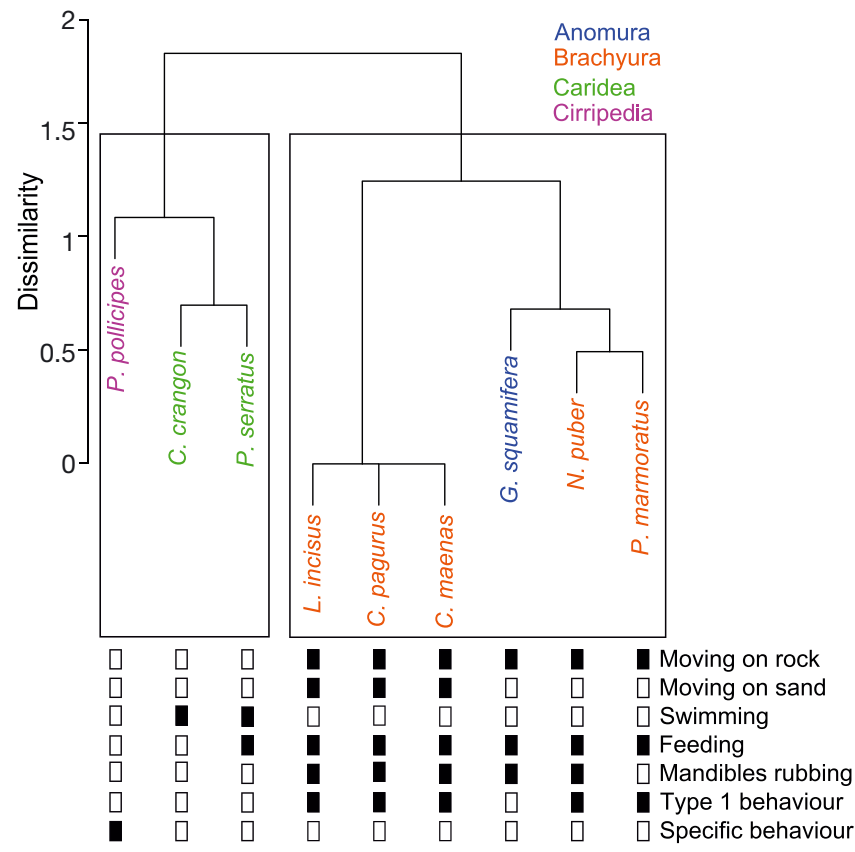

Fig. 4. Cluster analysis comparing the species for presence/ absence of acoustic behaviour using the Jacquard index (black $=$ presence; white $=$ absence $)$. See Table 1 for full species names

squamifera and Carcinus maenas had distinct feeding spectral characteristics, whereas Cancer pagurus and Pachygrapsus marmoratus had similar feeding acoustic spectral shapes, as did Palaemon serratus and L. incisus.

The EDDs were greater for Anomura and Brachyura than for Caridea and Cirripedia, which presented EDDs $<1 \mathrm{~m}$ in all 3 conditions, i.e. Wenz $1 \mathrm{kn}$, Wenz $5 \mathrm{kn}$ and in situ ANL. The majority of the acoustic behaviours of C. pagurus and N. puber showed high

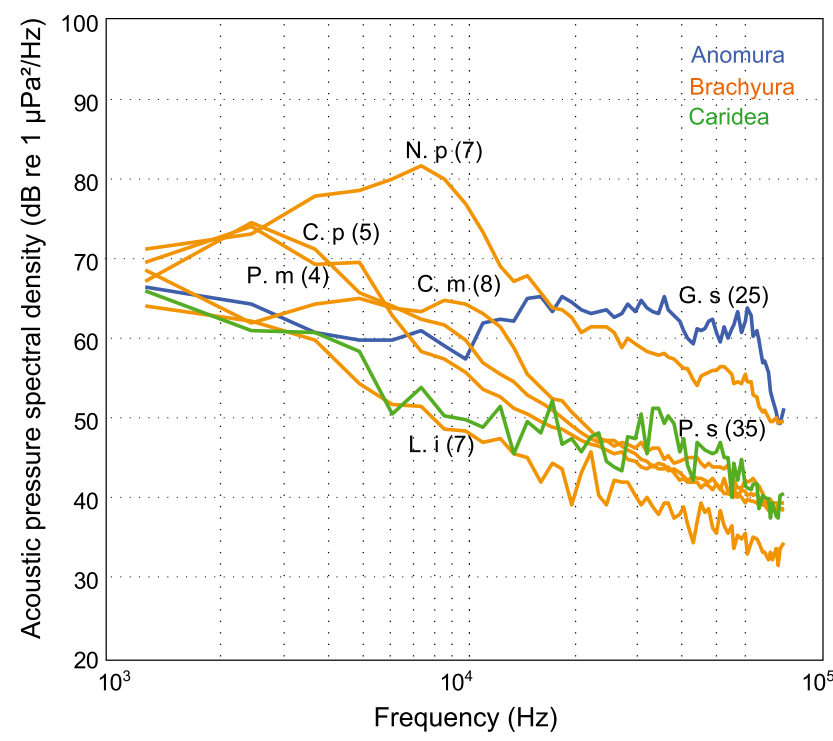

Fig. 6. Average acoustic spectra $\left(1 \mu \mathrm{Pa}^{2} \mathrm{~Hz}^{-1}\right.$ at $\left.1 \mathrm{~m}\right)$ of the stack of all signal selections for feeding sound types emitted by crustacean species living in NE Atlantic coastal habitats (128-point fast Fourier transform, rectangular window with $50 \%$ overlap). Numbers in parentheses correspond to the peak frequencies of the sounds (in $\mathrm{kHz}$ ). Species: Anomura Galathea squamifera (G. s); Brachyura Cancer pagurus (C. p), Carcinus maenas (C. m), Necora puber (N. p), Pachygrapsus marmoratus (P. m) and Lophozozymus incisus (L. i); Caridea Palaemon serratus (P. s)

EDDs at low wind regimes. Sounds associated with feeding for Brachyura and with moving on sand and Type 1 behaviour for $C$. pagurus, $N$. puber and $L$. incisus all showed high EDD values (up to $39.0 \mathrm{~m}$ in high wind conditions and up to $28.9 \mathrm{~m}$ with in situ ANL). In contrast, sounds associated with moving on rock, mandible rubbing, swimming and the majority of species-specific behaviours had lower EDD values
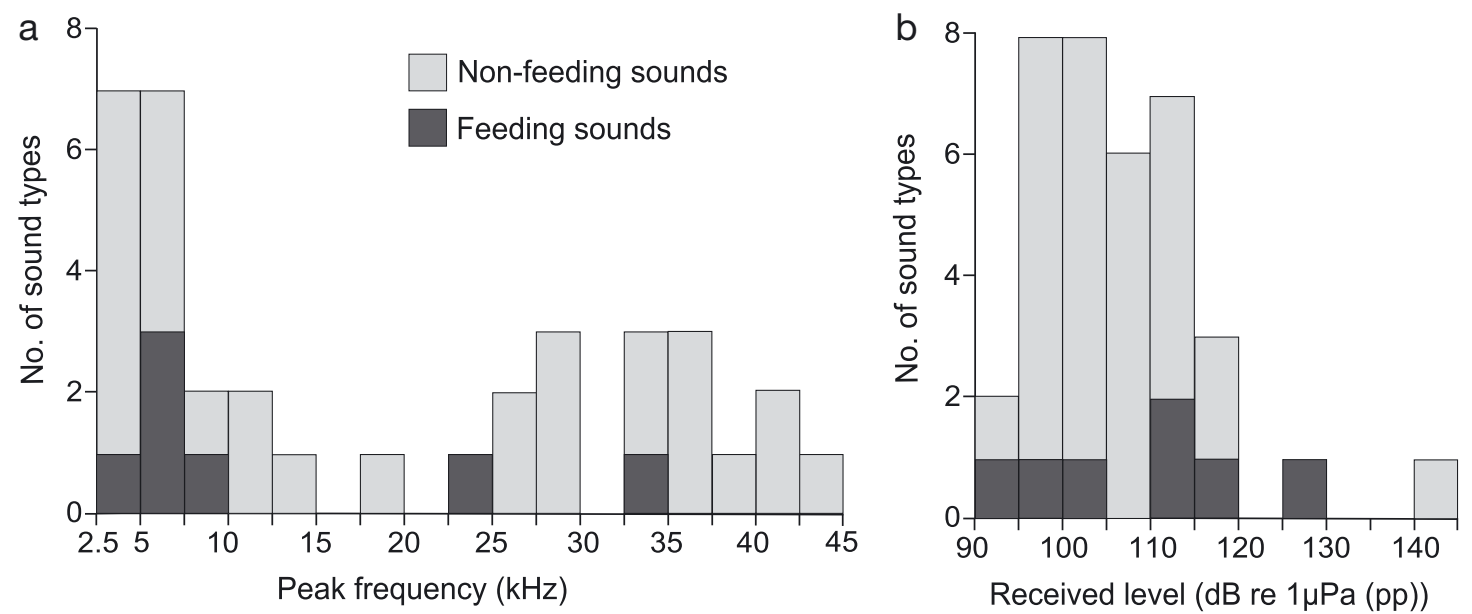

Fig. 5. (a) Peak frequencies and (b) received levels of sound types recorded from crustacean species living in NE Atlantic coastal habitats. The sounds were produced during feeding behaviour and during non-feeding behaviours that included moving, swimming, mandible rubbing, Type 1 and species-specific behaviours. pp: peak to peak 
in the $5 \mathrm{kn}$ wind and in situ ANL settings. Tables S1 \& S2 in Supplement 2 at www.int-res.com/articles/ suppl/b025p151_supp/ lists the acoustic feature values (RL, $f_{\mathrm{p}}$, bandwidth, in situ EDD) of each soniferous crustacean and the associated behaviours recorded in this study.

\section{Comparison of sound characteristics}

The sound types were compared between species and according to the behaviours. The sounds could be categorised into 2 groups based on their acoustic features, especially the $f_{\mathrm{p}}$ value (Fig. 7). The first group was composed mainly of sounds associated with moving on rock, feeding (for the Brachyura), Type 1 and moving on sand. This group was characterised by a low $f_{\mathrm{p}}$ (from 2 to $20 \mathrm{kHz}$ ), and the majority of sounds had high RL values (up to $142 \mathrm{~dB}$ re $1 \mu \mathrm{Pa}[\mathrm{pp}])$. The second group was composed of sounds generated by body parts rubbing together, including sounds associated with swimming, mandible rubbing and species-specific behaviours. This group was characterised by high $f_{\mathrm{p}}$ (from 25 to $45 \mathrm{kHz}$ ) and low RL values (up to $116 \mathrm{~dB}$ re $1 \mu \mathrm{Pa}[\mathrm{pp}])$.

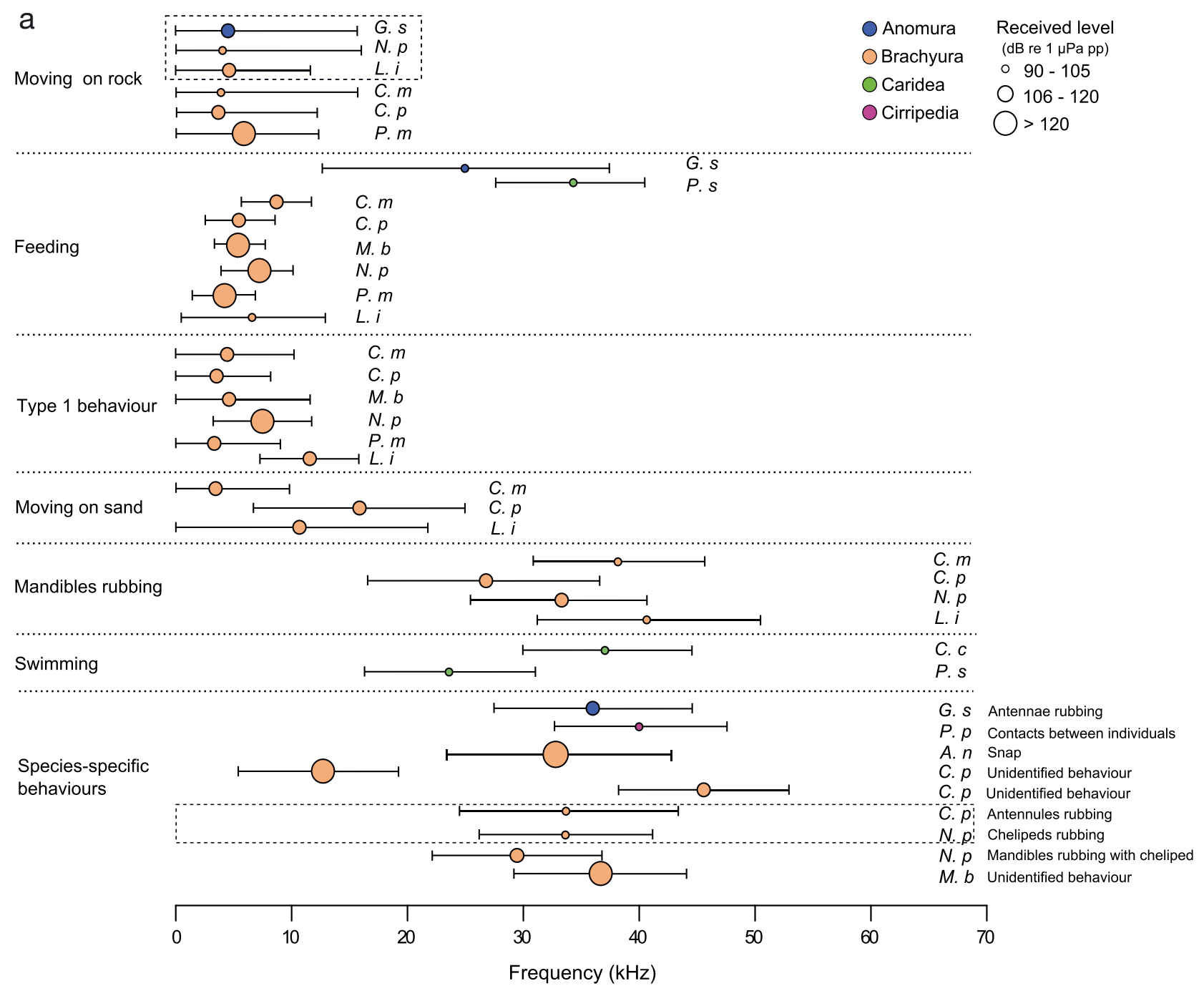

Fig. 7. Acoustic features of sounds recorded by (a) behaviour types and (b) taxa. The median peak frequencies are indicated by circles along with the bandwidths for the species: Galathea squamifera (G. s), Cancer pagurus (C. p), Carcinus maenas (C. m), Necora puber (N. p), Pachygrapsus marmoratus (P. m), Lophozozymus incisus (L. i), Crangon crangon (C. c), Palaemon serratus (P. s) and Pollicipes pollicipes (P. p). The circle size varies according to the classes of the received levels. The dotted boxes indicate species that did not differ significantly from each other in terms of peak frequency, received level or pulse sequence features (Kruskal-Wallis multiple comparison test). Data from Maja brachydactyla (M. b) and Athanas nitescens (A. n) originated from Coquereau et al. (2016). pp: peak to peak 
The Maja brachydactyla feeding sound had acoustic features that were similar to the feeding sounds recorded in this study for the Brachyura, as did the sound associated with Type 1 behaviour (Fig. 7a). The snapping sound made by Athanas nitescens matched the louder sounds recorded in this study and with sounds in the group that had high $f_{\mathrm{p}}$ values.

The acoustic features $f_{\mathrm{p}}$, RL or both differed significantly within and across behaviours (KruskalWallis multiple comparison tests, $\mathrm{p}<0.05$ ) (Figs. $7 \mathrm{a}$ $\&$ 8). Only the following did not show significant differences between species in terms of $f_{\mathrm{p}}$ and RL values (Kruskal-Wallis multiple comparison test, $\mathrm{p}>$ 0.05): moving on rock for N. puber, G. squamifera and $L$. incisus; species-specific behaviours for $N$. puber and C. pagurus; and Type 1 behaviour for $C$. maenas and $C$. pagurus. However, for the sound associated with Type 1 behaviour, which was a pulse train sound, the duration of the entire signal and the pulse-to-pulse time interval were significantly different between $C$. maenas and C. pagurus (Mann-Whitney $U$-test, $\mathrm{p}<0.05$ for the duration of

b

인

G. squamifera

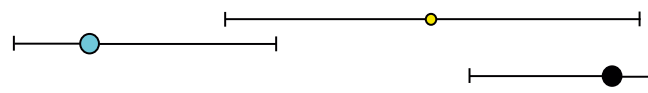

Moving (rock)

Moving (sand)

O Swimming

O Feeding

Mandibles rubbing

Type 1 behaviour

- Species-specific behaviours

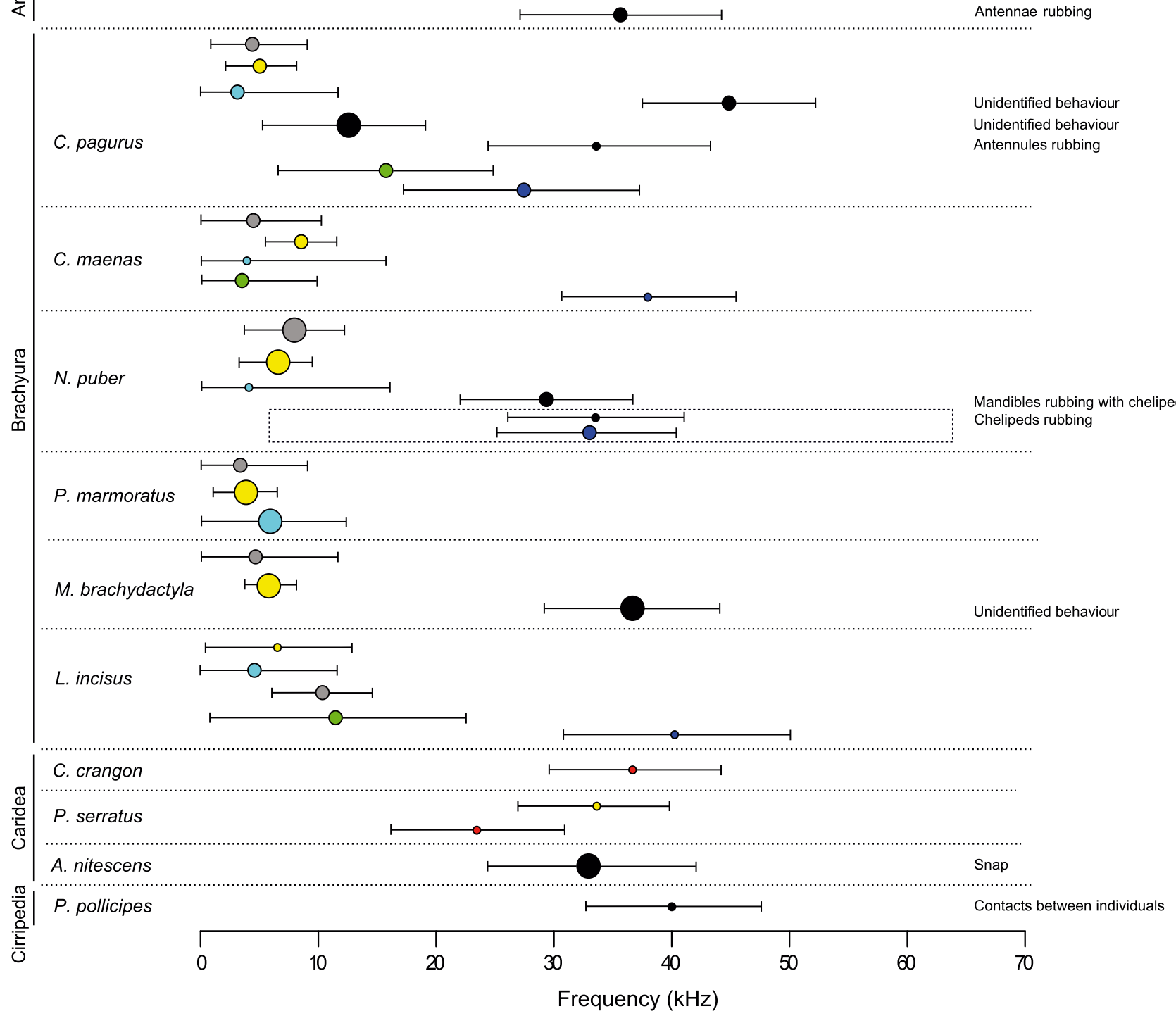

Fig. 7 (continued) 


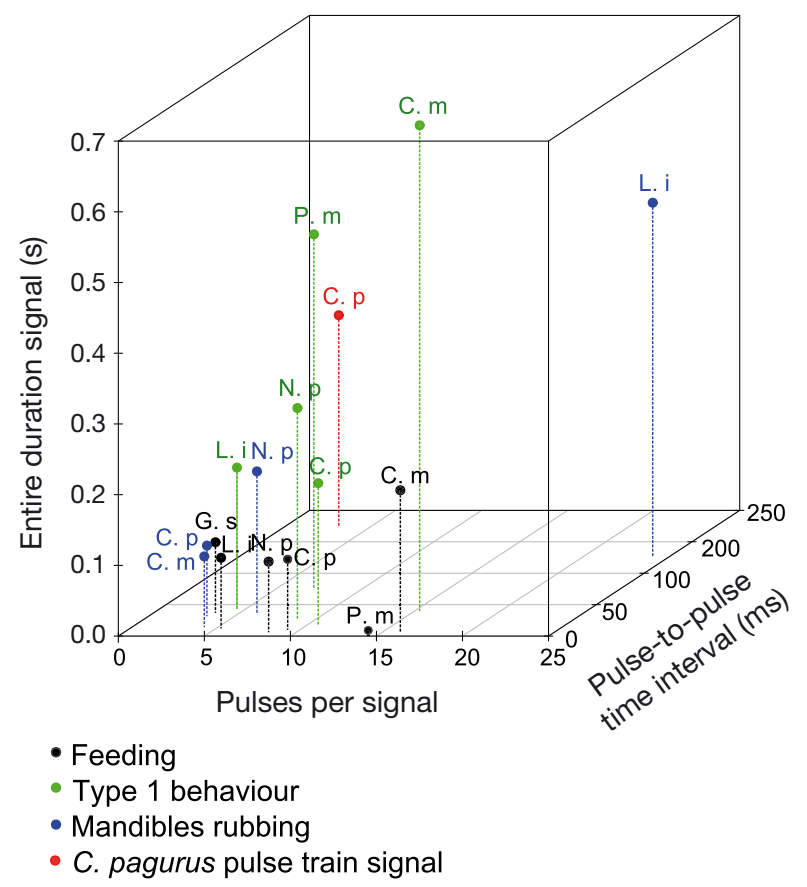

Fig. 8. Characteristics of the pulse train sounds produced by crustacean species living in NE Atlantic coastal habitats. Data points indicate the average for each crustacean species according to a particular behaviour. Species: Galathea squamifera (G. s), Cancer pagurus (C. p), Carcinus maenas (C. m), Necora puber (N. p), Pachygrapsus marmoratus (P. m), Lophozozymus incisus (L. i), Crangon crangon (C. C),

Palaemon serratus (P. s) and Pollicipes pollicipes (P. p)

the entire signal; $\mathrm{p}<0.001$ for the pulse-to-pulse time interval) (Fig. 8).

The acoustic features varied substantially both within and across the species (Figs. $7 b$ \& 8). The majority of the species (6 of the 9 soniferous species) had singular acoustic signatures for each of its behaviours in terms of $f_{\mathrm{p}}$, RL or both (Kruskal-Wallis multiple comparison test, $\mathrm{p}<0.05$ ) (Fig. 7b). However, 3 species had behaviours for which some of the sounds overlapped. $N$. puber showed 3 groups of sounds associated with behaviours; these sounds were not significantly different in terms of $f_{\mathrm{p}}$ RL or both (Kruskal-Wallis multiple comparison test, $\mathrm{p}<$ 0.05). The first group included sounds associated with feeding and Type 1 behaviour, the second group included sounds associated with mandible rubbing and species-specific behaviours and the third group included sounds associated with moving on rock behaviour. However, the sounds associated with feeding and Type 1 behaviour in the first group could be differentiated, as the pulse-to-pulse time intervals differed significantly (Mann-Whitney $U$-test, $\mathrm{p}<$ 0.001). For L. incisus and C. pagurus, the sounds associated with feeding, moving on rock and Type 1 behaviours did not differ significantly from each other (Kruskal-Wallis multiple comparison test, $\mathrm{p}>$ 0.05). Sounds associated with moving on rock could be distinguished from the other 2 sounds by the acoustical shape (single pulse vs. pulse train signal). The sounds associated with feeding and Type 1 behaviours could be differentiated by the pulse-topulse time interval, the duration of the entire signal and the pulse rate for both species $L$. incisus and $C$. pagurus (Mann-Whitney $U$-test, $\mathrm{p}<0.01$ ) (Fig. 8).

\section{DISCUSSION}

Because reverberation influences the acoustic features of sounds, the effects of tank reverberation on sound characteristics have been addressed (Parvulescu 1964, 1967, Akamatsu et al. 2002). In their tank-based experimental study, Coquereau et al. (2016) used simulations to show that tank-induced errors do not significantly affect $f_{\mathrm{p}}$ estimations of the initial part of transient signals. Using this methodology, the data obtained in the present study are consistent with the results of that study regarding the acoustic features. The sounds from the 2 soniferous crustacean species Athanas nitescens and Maja brachydactyla as reported by Coquereau et al. (2016) were in accordance with those recorded in our study in terms of the $f_{\mathrm{p}}, \mathrm{RL}$, bandwidth, general signal shape and spectra. In addition, $M$. brachydactyla (Brachyura), shared sound types with the Brachyura recorded in our study (i.e. sounds associated with feeding and Type 1 behaviour) and had similar acoustic feature values.

This study, which recorded 11 crustacean species, is the most comprehensive acoustic study of crustaceans in temperate coastal habitats to date. Overall, 34 sound types from 9 species were detected. The recorded sounds were produced during common behaviours, such as moving, feeding and mandible rubbing, which occur year-round in the natural environment. Our study represents an approximate $40 \%$ increase in the total number of acoustic crustacean species found in NE Atlantic habitats (Buscaino et al. 2011, de Vincenzi et al. 2015, Coquereau et al. 2016).

Because our recordings were conducted in tanks, we could associate sound emissions with specific movements when the sounds were produced in an obvious behavioural context, such as when the animals rubbed calcareous parts together (for example, antenna rubbing for Galathea squamifera and cheliped rubbing for Necora puber). However, when 
some sounds were produced, we did not observe any movement before, during or after the sound emission, and the individuals were mostly immobile. These sounds may result from very small rubbing movements of 2 body parts of an individual, as found for other crustacean species, which is difficult to observe (Guinot-Dumortier \& Dumortier 1960, Boon et al. 2009). Buscaino et al. (2015) described the acoustic behaviour of the paddle crab Ovalipes trimaculatus. They showed that this species emitted pulse train signals similar in shape and acoustic features to those associated with the Type 1 behaviour in this study. For males and females, the authors reported $f_{\mathrm{p}}$ values of 3.5 and $4.8 \mathrm{kHz}$, respectively, and sound levels of 127 and $123 \mathrm{~dB}$ re $1 \mu \mathrm{Pa}$, respectively. They indicated that this sound plays a role in intraspecific communication and is related to sexual attraction. In addition, Buscaino et al. (2015) did not observe movement that was large enough to confirm the mechanism of sound generation, which is similar to our findings for Type 1 behaviour. In our recordings, the males and females were together; thus, the sound associated with Type 1 behaviour could have been emitted in such an interacting context (in reference to Buscaino et al. 2015). It would be interesting to conduct species-specific behaviour studies to investigate the mechanism of sound production during Type 1 behaviour and during the other unidentified behaviours that produced well-structured sounds. Indeed, these well-structured sounds were among the loudest sounds recorded in this study (up to $142 \mathrm{~dB}$ re $1 \mu \mathrm{Pa}$ [pp]) and were as loud as the snapping sounds of $A$. nitescens, which belongs to a family (Alpheidae) that produces some of the louder sounds in the oceans (Au \& Banks 1998, Ferguson \& Cleary 2001, Schmitz 2002). This implies that when numerous, these sounds contribute substantially to natural coastal soundscapes and could be detected in field recordings. Analysis of the well-structured sounds also showed that several species and behaviours may be differentiated using features such as the number of pulses per signal that are independent of sound frequency and levels and are therefore not influenced by some factors that cannot be controlled for when using passive acoustics. It would also be important to assess the potential communication aspect of these sounds and the variability of sound production between sexes.

Our data analysis showed that Brachyura produced the majority of sound types, up to 6 and 8 for $N$. puber and Cancer pagurus, respectively. Brachyura shared a number of acoustic behaviours with G. squamifera. The crustacean species were grouped according to taxonomy using their acoustic behaviours. So, for example, if Brachyura are present in an environment, one may expect to record these sound types. Similarly, if taxon-specific sounds are detected in field recordings, one may conclude that this taxon is present. During the night recordings, we did not detect sound types that differed from the daytime sound types, although many decapods are nocturnal and seek protective shelter during the day. Staaterman et al. (2010) compared the nocturnal acoustic behaviour of the California spiny lobster Panulirus interruptus in a tank vs. in the field. There was a more physically active behavioural response in the field than in the tank, but there were no differences in the sounds that were produced. They also found that lobsters in tanks responded more actively to intrusion during the day compared to the night, but their rasping behaviour did not change depending on the time of day. Another study showed that the Japanese spiny lobster $P$. japonicus did not produce different sounds at night than during the day, although the frequency of its stridulating sounds tended to increase at night (Kikuchi et al. 2015). Our results from the night parts of the recordings were consistent with these studies, and we think that the species we studied also make the same sounds at night as during the day. It would be interesting to perform additional night recordings for several $24 \mathrm{~h}$ cycles to see if the crustaceans we recorded would also increase their sound production frequency.

Using a combination of several acoustic features, such as $f_{\mathrm{p}}, \mathrm{RL}$, general signal shape, spectra and pulse train features, our study showed that the majority of crustacean sounds were likely to be differentiable according to species or behaviour. These results would be useful for the study of crustacean ecology, since sounds can provide information on presence and behaviours. This was an exploratory study, and it seems important in the future to record several species simultaneously to see if they can be differentiated based on an analysis of the sounds they produce. In future efforts, it would be interesting to use other approaches to better characterise and quantify the differences between the sounds, such as spectral entropy, spectral dissimilarity or waveform decompositions.

Among the sound types recorded in this study, a significant portion presented low EDDs ( $\leq 1 \mathrm{~m}$ ): $44 \%$ in low wind conditions, $64 \%$ in high wind conditions and $73 \%$ using in situ ANL. This implies that a majority of the sounds recorded have low potential of detection in field recordings. Nevertheless, by looking at high EDD values and by combining 
acoustic features, 8 of the 34 sounds recorded in this study have properties consistent with detectability and identification for in situ acoustic studies: the feeding sound of C. pagurus, Carcinus maenas, $N$. puber and Pachygrapsus marmoratus; the speciesspecific sound of C. pagurus and G. squamifera; and the sounds associated with Type 1 behaviour of Lophozozymus incisus and N. puber. It should be also pointed out that the in situ ANL used in this study was calculated in a temperate coastal habitat with very high diversity (up to 200 species $\mathrm{m}^{-2}$ ) (Barbera et al. 2003), which is therefore a noisy habitat. The species recorded in this study also live in other coastal habitats, such as soft-sediment habitats, that are less diverse and therefore probably less noisy. Consequently, the EDDs obtained using in situ ANL might be smaller than what would be found in other habitats. These data help approximate the detectability of species and acoustic behaviours in field recordings.

The sound library that was created in this study contributes to the documentation of crustacean acoustic behaviour. The ability to distinguish sounds at a precise taxon level and to associate sounds with behaviour suggests the potential value of acoustic monitoring of crustacean activities and ecology. For example, sounds produced during feeding behaviour could be used to demonstrate a correlation between rates of sound production and daily rhythms. On a broader scale, it may useful to monitor crustacean sound production over long periods of time to assess periodic population behaviour and migrations. Although specific experiments in the field are required to confirm the acoustic and behavioural findings presented here, this work demonstrates that crustaceans are substantial participants in the soundscape in NE Atlantic coastal habitats.

Acknowledgements. We thank Céline Liret, Dominique Barthélémy, Sébastien Delaporte, Marie-Pierre Pelecq and the aquariology staff at the Océanopolis public aquarium in Brest for providing technical support. We are grateful to the Chorus chair for allowing us to utilise their tanks. We also thank the IUEM diving team for animal sampling, Michel Salaün for the illustrations in Fig. 3 and Fabien Riera for providing the camera used for night recordings. This paper was performed in the framework of the international laboratory CNRS-INEE/UQAR-ISMER Benthic Biodiversity Ecology Sciences and Technologies (BeBEST), which is a Franco-Québecois research initiative about coastal ecology. This research was supported by the French ANR program MER CALME (Project ANR-12-ASTR-0021-03) and was performed as part of the doctoral thesis of L.C., who was supported by presidential grants, at the Université de Bretagne Occidentale.

\section{LITERATURE CITED}

Abele LG (1974) Species diversity of decapod crustaceans in marine habitats. Ecology 55:156-161

> Akamatsu T, Okumura T, Novarini N, Yan HY (2002) Empirical refinements applicable to the recording of fish sounds in small tanks. J Acoust Soc Am 112:3073-3082

Anderberg MR (1973) Cluster analysis for applications. Monographs and textbooks on probability and mathematical statistics. Academic Press, New York, NY

Au WW, Banks K (1998) The acoustics of the snapping shrimp Synalpheus parneomeris in Kaneohe Bay. J Acoust Soc Am 103:41-47

Barbera C, Bordehore C, Borg JA, Glémarec M and others (2003) Conservation and management of northeast Atlantic and Mediterranean maerl beds. Aquat Conserv Mar Freshw Ecosyst 13:S65-S76

Bohnenstiehl DR, Lillis A, Eggleston DB (2016) The curious acoustic behavior of estuarine snapping shrimp: temporal patterns of snapping shrimp sound in sub-tidal oyster reef habitat. PLOS ONE 11:e0143691

Boon PY, Yeo DCJ, Todd PA (2009) Sound production and reception in mangrove crabs Perisesarma spp. (Brachyura: Sesarmidae). Aquat Biol 5:107-116

Boudreau SA, Worm B (2012) Ecological role of large benthic decapods in marine ecosystems: a review. Mar Ecol Prog Ser 469:195-213

> Bouwma PE, Herrnkind WF (2009) Sound production in Caribbean spiny lobster Panulirus argus and its role in escape during predatory attack by Octopus briareus. N Z J Mar Freshw Res 43:3-13

Brown C, Bennett D (1980) Population and catch structure of the edible crab (Cancer pagurus) in the English Channel. $\mathrm{J}$ Cons Int Explor Mer 39:88-100

Budelmann BU (1992) Hearing in Crustacea. In: Webster D, Popper A, Fay R (eds) The evolutionary biology of hearing. Springer, New York, NY, p 131-139

> Buscaino G, Filiciotto F, Gristina M, Bellante A and others (2011) Acoustic behaviour of the European spiny lobster Palinurus elephas. Mar Ecol Prog Ser 441:177-184

- Buscaino G, Gavio A, Galvan D, Filiciotto F and others (2015) Acoustic signals and behaviour of Ovalipes trimaculatus in the context of reproduction. Aquat Biol 24: 61-73

Butler J, Stanley JA, Butler MJ IV (2016) Underwater soundscapes in near-shore tropical habitats and the effects of environmental degradation and habitat restoration. J Exp Mar Biol Ecol 479:89-96

Coquereau L, Grall J, Chauvaud L, Gervaise C, Clavier J, Jolivet A, Di Iorio L (2016) Sound production and associated behaviours of benthic invertebrates from a coastal habitat in the north-east Atlantic. Mar Biol 163:127

$>$ de Vincenzi G, Filiciotto F, Maccarrone V, Mazzola S, Buscaino G (2015) Behavioural responses of the European spiny lobster, Palinurus elephas (Fabricius, 1787), to conspecific and synthetic sounds. Crustaceana 88: 523-540

Ewing AW (1989) Arthropod bioacoustics: neurobiology and behaviour. Cornell University Press, Ithaca, NY

- Ferguson BG, Cleary JL (2001) In situ source level and source position estimates of biological transient signals produced by snapping shrimp in an underwater environment. J Acoust Soc Am 109:3031-3037

- Freeman SE, Rohwer FL, D'Spain GL, Friedlander AM, Gregg AK, Sandin SA, Buckingham MJ (2014) The 
origins of ambient biological sound from coral reef ecosystems in the Line Islands archipelago. J Acoust Soc Am 135:1775-1788

Grall J (2002) Biodiversité spécifique et fonctionnelle du maerl: réponses à la variabilité de l'environnement côtier. PhD dissertation, Université de Bretagne Occidentale, Plouzané

Guinot-Dumortier D, Dumortier B (1960) La stridulation chez les crabes. Crustaceana 1:117-155

Henninger HP, Watson WH (2005) Mechanisms underlying the production of carapace vibrations and associated waterborne sounds in the American lobster, Homarus americanus. J Exp Biol 208:3421-3429

Hollander M, Wolfe DA, Chicken E (2014) Nonparametric statistical methods, 3rd edn. John Wiley \& Sons, New York, NY

> Johnson ML, Gaten E, Shelton PM (2002) Spectral sensitivities of five marine decapod crustaceans and a review of spectral sensitivity variation in relation to habitat. J Mar Biol Assoc UK 82:835-842

Kikuchi M, Akamatsu T, Takase T (2015) Passive acoustic monitoring of Japanese spiny lobster stridulating sounds. Fish Sci 81:229-234

Knowlton RE, Moulton JM (1963) Sounds production in the snapping shrimps Alpheus (Crangon) and Synalpheus. Biol Bull 125:311-331

Moulton JM (1957) Sound production in the spiny lobster Panulirus argus (Latreille). Biol Bull 113:286-295

Parvulescu A (1964) Problems of propagation and processing. In: Tavolga WN (ed) Marine bioacoustics. Pergamon Press, Oxford, p 87-100

Parvulescu A (1967) The acoustics of small tanks. Marine bio-acoustics. In: Tavolga WN (ed) Marine bioacoustics. Pergamon Press, Oxford, p 7-13

Patek SN (2002) Squeaking with a sliding joint: mechanics and motor control of sound production in palinurid lobsters. J Exp Biol 205:2375-2385

Patek SN, Baio J (2007) The acoustic mechanics of stick-slip friction in the California spiny lobster (Panulirus inter-

Editorial responsibility: Bernard Sainte-Marie, Mont-Joli, Quebec, Canada ruptus). J Exp Biol 210:3538-3546

Patek SN, Caldwell R (2006) The stomatopod rumble: low frequency sound production in Hemisquilla californiensis. Mar Freshwat Behav Physiol 39:99-111

Patek SN, Oakley T (2003) Comparative tests of evolutionary trade offs in a palinurid lobster acoustic system. Evolution 57:2082-2100

Piercy JJB, Codling EA, Hill AJ, Smith DJ, Simpson SD (2014) Habitat quality affects sound production and likely distance of detection on coral reefs. Mar Ecol Prog Ser 516:35-47

Schmitz B (2002) Sound production in Crustacea with special reference to the Alpheidae. In: Wiese K (ed) The crustacean nervous system. Springer, New York, NY, p 536-547

Sheehy MRJ, Prior AE (2008) Progress on an old question for stock assessment of the edible crab Cancer pagurus. Mar Ecol Prog Ser 353:191-202

Staaterman E, Claverie T, Patek SN (2010) Disentangling defense: the function of spiny lobster sounds. Behaviour 147:235-258

Stanley JA, Radford CA, Jeffs AG (2010) Induction of settlement in crab megalopae by ambient underwater reef sound. Behav Ecol 21:113-120

Strauss J, Dircksen H (2010) Circadian clocks in crustaceans: identified neuronal and cellular systems. Front Biosci 15:1040-1074

- Versluis M, Schmitz B, von der Heydt A, Lohse D (2000) How snapping shrimp snap: through cavitating bubbles. Science 289:2114-2117

Ward D, Morison F, Morrissey E, Jenks K, Watson WH III (2011) Evidence that potential fish predators elicit the production of carapace vibrations by the American lobster. J Exp Biol 214:2641-2648

> Watanabe M, Sekine M, Hamada E, Ukita M, Imai T (2002) Monitoring of shallow sea environment by using snapping shrimps. Water Sci Technol 46:419-424

Wenz GM (1962) Acoustic ambient noise in ocean spectra and sources. J Acoust Soc Am 34:1936-1956

Submitted: July 13, 2016; Accepted: September 26, 2016

Proofs received from author(s): October 21, 2016 